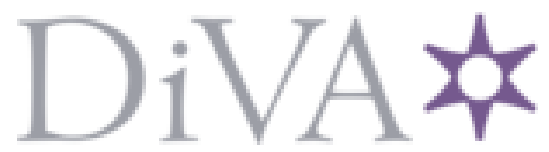

http://www.diva-portal.org

\title{
Postprint
}

This is the accepted version of a paper published in Research in Science \& Technological Education. This paper has been peer-reviewed but does not include the final publisher proof-corrections or journal pagination.

Citation for the original published paper (version of record):

Haglund, J., Melander, E., Weiszflog, M., Andersson, S. (2017)

University physics students' ideas of thermal radiation expressed in open laboratory activities using infrared cameras.

Research in Science \& Technological Education, 35(3): 349-367

https://doi.org/10.1080/02635143.2017.1318362

Access to the published version may require subscription.

N.B. When citing this work, cite the original published paper.

Permanent link to this version:

http://urn.kb.se/resolve?urn=urn:nbn:se:uu:diva-326285 


\section{University physics students' ideas of thermal radiation expressed in open laboratory activities using infrared cameras}

Jesper Haglund*, Emil Melander, Matthias Weiszflog, Staffan Andersson

Department of Physics and Astronomy, Uppsala University, Uppsala, Sweden

*Corresponding author

Full address: Department of Physics and Astronomy, Uppsala University, Box 516, 75120 Uppsala, Sweden

telephone: +46-18-4713544, email: jesper.haglund@physics.uu.se

telephone: +46-18-4713840, email: emil.melander@physics.uu.se

telephone: +46-18-4713051, email: matthias.weiszflog@physics.uu.se

telephone: +46-18-4713520, email: staffan.andersson@physics.uu.se

This is a prepublished version of Haglund, J., Melander, E., Weiszflog, M., \& Andersson, S. (2017). University physics students' ideas of thermal radiation expressed in open laboratory activities using infrared cameras. Research in Science \& Technological Education, 35(3), 349-367. Please cite the original article. 


\section{Structured abstract}

Background

University physics students were engaged in open-ended thermodynamics laboratory activities with a focus on understanding a chosen phenomenon or the principle of laboratory apparatus, such as thermal radiation or a heat pump. Students had access to handheld infrared (IR) cameras for their investigations.

Purpose

The purpose of the research was to explore students' interactions with reformed thermodynamics laboratory activities. It was guided by the research question: How do university physics students make use of IR cameras in the investigation of the interaction of thermal radiation?

Sample

The study was conducted with a class of first-year university physics students in Sweden. The interaction with the activities of four of the students was selected for analysis. The four students are males.

Design and methods

We used a qualitative, interpretive approach to the study of students' interaction. The primary means of data collection was video recording of students' work with the laboratory activities and their subsequent presentations. The analysis focused on how IR cameras helped students notice phenomena relating to thermal radiation, with comparison to previous research on students' conceptions of thermal radiation.

Results

When using the IR camera students attended to the reflection of thermal radiation on shiny surfaces, such as polished metals, windows or a white-board, and emissive properties of surfaces of different types. In this way, they went beyond 
using the technology as a temperature probe. Students were able to discuss merits and shortcomings of IR cameras in comparison with digital thermometers.

Conclusions

With the help of IR cameras, university physics students attend to thermal phenomena that would otherwise easily go unnoticed.

Keywords: Infrared cameras; Thermal radiation; Open laboratory exercises; Physics education

\section{Introduction}

Disciplinary-based educational research in chemistry (Bain et al. 2014) and physics (Dreyfus et al. 2015) has found that thermodynamics is a complex and challenging area of learning, partly due to the abstract nature of the subject. In addition, an international questionnaire study revealed that engineering students found thermodynamics to be average or higher than average in terms of difficulty compared to other engineering courses, and - unfortunately - not very interesting to learn (Ugursal and Cruickshank 2015). In the teaching of thermodynamics across different academic disciplines, we are therefore confronted with the challenge of making the subject more understandable and accessible to our students. The use of infrared (IR) cameras, in particular in conjunction with more open-ended inquiry-based laboratory exercises, offers one useful approach to take on this challenge (Xie and Hazzard 2011). Working with IR cameras enables students to access and literally see thermal phenomena in new ways.

This study reports on undergraduate physics students' interaction and communication during an open-ended thermodynamics laboratory module, where they had the opportunity to engage in investigations of thermal phenomena with IR cameras. As students tended to focus on thermal radiation, and given previous research on students' lacking knowledge on the topic (e.g. Redfors and Ryder 2001, Besson, De Ambrosis, and Mascheretti 2010), this became our main area of study. 


\section{Thermal radiation in history}

We start by giving a brief description of how the phenomenon of thermal radiation has been studied in the history of science, in order to see how the ideas and questions of historical scientists, and the experimental apparatus they used, can still be relevant in the teaching of thermal science.

Thermal radiation has long fascinated humanity. The fire-lighting technique using 'burning glasses' to concentrate the sun's rays to start burning has been known since classical times. In his study of radiant heat in the history of science, Cornell (1936) acknowledges Bacon (1620/2000) for suggesting the use of such burning glasses for the study of heat from objects that are not glowing, such as heated stones or boiling water. At the same time, Cornell (1936, 219) attributes 'The first systematic series of experiments on Radiant Heat' to Scheele, “who made a praiseworthy effort to harmonise theory with experiment, and succeeded in producing a theory of radiant heat and light which was perhaps the best attainable in the light of the then prevailing Phlogiston Theory, and with the facts then available”. Based on his experiments of shielding the heat from a burning stove with glass and metal plates, Scheele (1777/1780, 7374) eloquently concludes in the late $18^{\text {th }}$ century:

Hence it follows, that the heat passing through the door of the stove coincides, in some points, with the light, but is not yet quite become light, since it is not reflected in the same manner from a glass surface as from a metallic one - a remarkable circumstance! /.../ Represent to yourself a little hillock of burning coals; in this case the heat darting from this hillock all around, is that which may be reflected by a metallic polished plate; that on the contrary which rises upwards, and may be driven by winds to and fro, unites with Air. I will call the first kind, for distinction sake, radiant heat.

In modern terms, Scheele distinguishes between two of the mechanisms of heat transfer conduction and radiation - and shows how IR radiation shares some, but not all, properties with visible light. 
In the early $19^{\text {th }}$ century, much use was made of Leslie's (1804) cube in the investigation of the thermal and optical properties of heat radiation (Olson 1969). A Leslie's cube is a metal container, the surfaces of which have different properties, typically one shiny metal side and a matte metal side, and two black and white painted sides respectively. The radiation emitted from the surfaces can be studied as the temperature of the cube's interior is controlled, for example by hot water or with a lamp. Leslie’s cube is still useful for educational purposes. For instance, it can be used to show that matte black and matte white surfaces have roughly the same emissivity in the infrared range (Bartels 1990), which often comes as a surprise to students given that their difference in emissivity in the visual range is what makes one surface appear as black and the other as white. In fact, white surfaces serve as quite good "black bodies" in far infrared wavelengths.

Subsequent, important discoveries in relation to thermal radiation include Herschel's (1800) finding that solar radiation beyond the red part of the spectrum - later labelled infrared - causes heating, Maxwell's (1865) identification of visible light as a type of electromagnetic radiation, and Planck’s (1901) theory of black-body radiation.

\section{Students' understanding of thermal radiation}

Thermal radiation can be characterised as the form of electromagnetic (EM) radiation that is emitted by bodies because of their temperature (Çengel and Turner 2005). Although thermal radiation has a central role in the history of physics, it has not been a prominent topic in educational research. This is indicated by the fact that it is not mentioned in a recent resource letter on the teaching of thermodynamics and statistical mechanics drawing on discipline-based education research from physics, chemistry, and biology (Dreyfus et al. 2015). However, a few studies have been conducted on students' understanding of thermal radiation.

Regarding the understanding of radiation amongst younger students, Neumann and Hopf (2012) conducted an interview study with $9^{\text {th }}$ graders on the topic. They found that the 
majority of students had negative feelings about the word 'radiation' in general. This was because they saw radiation as something artificial and/or associated to risks of nuclear radiation, mobile phone use, or being exposed to sunlight. Only a few of them identified visible light as a type of radiation, and a majority related infrared radiation to mobile phones (for which IR interfaces were in common use at the time of the interviews). Neumann and Hopf concluded that this understanding of radiation as something unnatural and harmful is narrow, and that students should be encouraged to broaden their view by considering other spontaneously occurring types of radiation, such as visible light and thermal radiation, and how radiation can be used in a beneficial way, for example in medical applications.

As for studies among university students, Redfors and Ryder (2001) investigated thirdyear university physics students' use of scientific models in their explanations of phenomena involving interactions between metals and electromagnetic radiation. They found that very few students made use of appropriate microscopic models of emission, reflection or absorption of radiation, involving unbound electrons in the metal. Besson et al. (2010) also studied university students' (some in physics) understanding of the interaction of radiation and matter, in the context of global warming. In an initial test, only a few students could account for the increased temperature in a greenhouse or global warming, in terms of solar radiation and thermal radiation emitted from the ground, due to 'a lacking or incorrect consideration of IR emission of bodies as a mechanism of losing energy' (378). In order to address the limited understanding, students investigated: what happens when different objects are exposed to solar radiation; IR radiation emission from different objects; optical properties of materials at different wavelengths of the radiation; and, the energy fluxes of a model greenhouse. For example, following Bartels (1990), students compared the temperature changes of three metal cylinders, one painted black, one painted white and one with a shiny metal surface, otherwise identical, when exposed to light from a lamp and then allowed to cool down. As an outcome of the course, the participating 
students were found to have gained an appreciation of the wavelength dependence of the optical properties for materials and having developed a better understanding of the greenhouse effect.

As one of three mechanisms of heat transfer (Çengel and Turner 2005), students’ ideas of thermal radiation have also been investigated using concept inventories in engineering education. Jacobi, et al. (2003) report on the development of a Heat Transfer Concept Inventory, which was designed in relation to an upper-level engineering course on heat transfer. Student responses in the pilot study are quite discouraging. For example, when asked to list topics or concepts from the course that they were most or least confident with, one of the students responded that he was not confident about "the difference between convection, conduction and radiation” (13). Similarly, another student said: “I get confused about all those terms: emissivity, absorptivity, reflectivity, transmissivity” (15). A defeatist spirit is revealed in the following quotes: “I don’t understand radiation but I'm OK with it” (15) and "Electromagnetic radiation is impossible to understand" (15). Jacobi et al. conclude that while students may be able to solve quantitative problems, their understanding of the underlying physical phenomena involved in heat transfer is limited. Prince, Vigeant and Nottis (2012a) report obtaining similar initial results from the development and testing of the Heat and Energy Concept Inventory (also in relation to undergraduate heat transfer courses, with thermal radiation as one of the focus areas). Overall, participating students' pretest scores and learning gains on thermal radiation were disappointingly small. For example, only a minority of students were able to conclude that the rate of heat loss from a black painted metal surface is higher than that from a shiny metal surface (33.7 \% in pretest, and $42.8 \%$ in posttest), with the most common justification being that the black surface absorbs and holds the heat better.

Viennot and Décamp (2016) investigated the function of survival blankets, where one side is more reflective than the other, and students' understanding of how the blanket should be used. Questionnaires to $\mathrm{PhD}$ students and interviews with preservice physics and chemistry 
teachers revealed an understanding that went little further than survival blankets reflect infrared radiation from human bodies. The basic reasoning problem that Viennot and Décamp identified was that, despite having the knowledge to do otherwise, students tend to call on simplistic explanatory models in their discussions on how a survival blanket works. For example, relevant factors, such as conductive or convective energy transfer, were ignored when assessing which of the sides of the blanket was the most reflective and which side should be turned towards, and which away from a body to help protect it from excessive cooling.

\section{Laboratory exercises in science education}

One potential way to address student learning difficulties in the area of thermal radiation is through practical laboratory exercises. However, reviews on the general topic of educational laboratory exercises have shown that these are often carried out without a clear learning objective, and against a background of limited empirical evidence of the effects on students' learning outcomes (Hofstein and Lunetta 2004, Tobin 1990). Hake (1998) has shown that traditional teaching, in which students typically follow recipe-like labs with limited opportunities for interactive engagement with peers and teachers, is associated with low learning gains on the Force Concept Inventory (FCI) test (Hestenes, Wells, and Swackhamer 1992). Similarly, Hofstein and Lunetta (2004) argue that although laboratory activities have the potential to support science learning, this is inhibited when students are expected to follow 'cookbook’ instructions that provide limited opportunities for minds-on engagement.

If the goal is for students to develop conceptual understanding and associated problemsolving skills, or their creativity, other more open-ended approaches are worth considering (Domin 1999). These include inquiry approaches, guided by students' own questions, or discovery and problem-based approaches, where students are given more autonomy in how to investigate predetermined phenomena. Here, the educational challenge is to provide sufficient 
guidance in written instructions and in student-teacher dialogue, without stifling students' ownership of their learning.

In his meta-study of physics students' results on the FCI test, Hake (1998) found that significantly higher learning gains were possible with interactive-engagement approaches (including inquiry-based laboratory activities) compared to traditional teaching. In particular, following principles for design of inquiry activities within Workshop Physics (Laws et al. 1997), Prince, Vigeant and Nottis (2012b) found significant, and relatively high learning gains in relation to the Heat and Energy Concept Inventory (Jacobi et al. 2003) in the area of thermal radiation among engineering students who had engaged in related inquiry-based activities (37 $\%$, compared to $11 \%$ in a control group with traditional teaching).

\section{IR cameras in physics education}

IR cameras offer a potential tool for enhancing laboratory exercises relating to thermal radiation (Vollmer et al. 2001, Haglund et al. 2015b). An IR camera measures the intensity of electromagnetic radiation, which is emitted from all matter above the temperature $0 \mathrm{~K}$. In normal classroom conditions, the radiation is dominated by the infrared range. Using Planck's law of black-body radiation, together with assumptions of the emissivity, the temperature of different points on a surface are derived and rendered on a screen where different colours represent the temperature range (Vollmer and Möllmann 2010). Many materials have emissivities close to 0.95 , such as wood, plastics, stone, or painted metal surfaces. However, shiny surfaces, such as polished metal, may have considerably lower emissivity values (The_Engineering_Toolbox 2016), which yield lower IR-camera readings.

Handheld IR cameras have been developed for industrial purposes. Decreasing prices recently have made the technology an increasingly viable option also for teaching purposes. In a set of studies, Vollmer and colleagues (Vollmer et al. 2001, Möllmann and Vollmer 2007, 
Vollmer and Möllmann 2010) have suggested phenomena and applications, where IR imaging can bring added value in teaching for a range of science and engineering topics.

Due to the versatility of the technology, Xie (Xie 2011, Xie and Hazzard 2011) sees particular benefit from the incorporation of IR cameras into inquiry-based approaches to physics and chemistry education, as students are allowed to see the mechanisms of heat transfer. Similarly, following a study of visitors' interactions with an IR-camera-based exhibit at a science centre, Atkins et al. (2009) observed how many visitors engaged with the technology in inventive and creative ways with minimal instructions, such as rubbing their hands or bringing in snow from outdoors and observing it melt.

Although students have been found to use IR cameras to measure and visualise temperature (Haglund et al. 2015a), the technology can also be fruitfully used in the investigation of the thermal behaviour of electromagnetic radiation at different wavelengths. Here, Möllmann and Vollmer (2007) suggest studying radiation in relation to a Leslie’s cube by means of an IR camera. Similarly, Planinsic (2015) has developed a set of student exercises for the study of the emissive and absorptive properties of surfaces of different colour in the visible light, near-infrared (by use of a digital camera with an infrared filter) and far-infrared electromagnetic spectra (with IR cameras).

We have taken part in design studies of the use of IR cameras in the teaching of thermal science spanning grades 4-12 (Haglund et al. 2015b, a, Haglund, Jeppsson, and Schönborn 2016, Schönborn, Haglund, and Xie 2014). Based on a predict-observe-explain approach (White and Gunstone 1992), students at all these age levels were found to learn quickly to use the technology. Similar to what Atkins et al. (2009) found, students often came up with inventive ways to use the IR cameras, such as investigating what happens to the temperature of hot water if you blow on its surface; cases of 'instant inquiry' (Haglund, Jeppsson, and Schönborn 2016). Still, even with access to thermal imaging technology, students found some 
thermal phenomena challenging to understand. In particular, they had difficulties figuring out why metals feel colder than wood when they are both at room temperature. $7^{\text {th }}$ graders used the IR cameras merely as temperature measurement devices, rather than interpreting the phenomenon as a 'heat flow' from their hands to the objects(Schönborn, Haglund, and Xie 2014). As a parallel to novices not trusting traditional thermometer readings of temperatures of metals (Lewis and Linn 1994), we have found upper-secondary students dismissing IR-camera measurements of the temperature of a knife as due to reflections, because of a conflict with their tactile impression of the knife feeling cold (Haglund et al. 2015a).

\section{Purpose of the study}

In summary, previous research has found that students have difficulties understanding thermal radiation as a phenomenon, but that open-ended laboratory activities where students have the opportunity to engage in inquiry tend to lead to higher learning gains than traditional teaching approaches. In this regard, IR cameras have proven a promising technology for students' inquiry-based investigation of thermal phenomena. Against this background, the purpose of the present study was to see how university physics students could benefit from the use of IR cameras in their investigation of thermal phenomena, with a particular focus on thermal radiation as a phenomenon. The study was guided by the following research question: How do university physics students make use of IR cameras in open-ended investigation of thermal radiation as a phenomenon?

\section{Method}

\section{Background to the study}

The studied laboratory module in thermodynamics was previously given in the form of a set of alternative 'cookbook' exercises, where students made measurements in a predetermined fashion and reported on the outcome, i.e. in an expository laboratory style (Domin 1999). 
Students had access to a well-equipped thermodynamics laboratory, including heat pumps, Leslie's cubes with thermometers, and experimental apparatus for measurement of heat conductivity of different materials. However, students' course evaluations revealed limited engagement with the taught content, as they focused on finishing the exercises and corresponding reports.

Starting in 2011, the module has been redesigned, with the rationale to make better use of existing equipment in supporting student engagement and reinforcing connections to underlying thermal phenomena in a more open-ended fashion (Melander, Gustavsson, and Weiszflog 2013, Melander et al. 2016). As part of the module development, IR cameras were added to the ways with which students could study the heat-related phenomena.

The present study was an qualitative, interpretative study (Cohen, Manion, and Morrison 2011) that involved 42 first-year Bachelor students majoring in physics, who were in an introductory course in thermodynamics during the spring 2015. The research context was the student laboratory for this course. The research was a collaborative effort between teachers on the course and education researchers.

\section{Instructional design}

When signing up for the laboratory module, students in groups of 2-3 were given a list of alternative phenomena or apparatus to choose from for their laboratory task: Plan and conduct a primarily qualitative investigation with the given equipment during the two-hour session. Then, they were provided texts and links to background information, video clips, etc., in order to be able to prepare for the tasks prior to coming to the laboratory. At the laboratory, they were given a brief introduction to the exercise and the different laboratory apparatus. The main purpose was for the students to get to understand the phenomenon or principle of the apparatus they were assigned to, and they were actively discouraged from making measurements and reporting them in a quantitative fashion. During the laboratory work, the students had access to 
four IR cameras (FLIR models C2, E4, and E6, which were set to measuring with the assumed emissivity of $\varepsilon=0.95$ ). The students' engagement with the laboratory exercises was assessed through oral presentations to the peer group one week after the practical investigations, with a focus on describing the chosen phenomena (Melander, Gustavsson, and Weiszflog 2013).

In the studied laboratory group, the phenomena or apparatus to choose from were (Melander et al. 2016):

- A heat pump

- $\quad$ Temperature and entropy of a rubber band

- The relation $C_{p} / C_{v}$ in different gases

- Heat conductivity of different solid materials

- Joule-Thompson cooling (with a fire extinguisher)

- Thermal radiation (with a Leslie’s cube)

- The function of IR cameras

\section{Data collection and analysis}

Students' interaction with the laboratory exercises and the subsequent presentations were captured with video and audio recording. Mounted video cameras placed at selected laboratory stations were used in conjunction with handheld video cameras. The handheld mode was used in order to be able to follow the activities in the laboratory in a flexible manner. It allowed one of the researchers to intervene briefly in interviews with the students and probe them regarding what they did and how they interpreted the situations at hand. In addition, students' captured IR images from the laboratory activities, their supplementary slide-show presentations, and additional still photo images of students' interactions with the apparatus were gathered. In line with international and local ethical guidelines, informed consent was gathered from all students prior to participation in the study. Pseudonym student names are used in the Results and photos 
of identifiable students are not related to analysed data.

A total of about 14 hours of video data was collected and reviewed. We have provided a general overview of our impressions of the students' interaction with the laboratory exercises, and their engagement with IR cameras elsewhere (Melander et al. 2016). For the purpose of the present study, three episodes of student interaction were purposively selected, based on the following criteria:

- Novelty, in the sense of situations where these university students differed markedly from what we have seen in secondary students' interaction with IR cameras. In particular, the university students used the IR cameras as a way to investigate thermal radiation as a phenomenon, rather than as temperature probes.

- Instances where IR cameras were found to be particularly useful in comparison to other alternative ways to approach the thermal phenomena at hand, such as thermometers or the senses of touch and vision.

- Expressions of a sense of insight, fascination, and surprise.

- Recurring themes, which were seen also amongst other student groups who chose to study the same phenomenon or apparatus.

The selected samples of student dialogue and presentations were transcribed and analysed qualitatively in the original Swedish, against the background of previous research on students' understanding of thermal radiation and interaction with IR cameras. For the purpose of illustrating the results, we share extended excerpts of students' dialogue and presentations translated into English.

\section{Results}

The three episodes presented here characterise how the students used IR cameras in the investigation of the interaction of thermal radiation with surfaces of different materials, and 
their consequent reflections on what they had learnt.

\section{Reflections on reflections - the function of a window}

Two students, Carl and Anders, choose the task of investigating the functionality of IR cameras, and come up with the idea of investigating the laboratory's windows facing outdoors (Figure 1). Halfway through their investigation, one of the researchers $(\mathrm{JH})$ asks Carl and Anders what they have seen:

JH: What did you see when you looked there?

Carl: I saw our reflections. Heat reflections. /.../ And also heat reflections from the lamps./.../ [points the IR camera to the window, so that heat reflections from the lamps are seen on the camera display]

JH: That's the lamps above us here... /.../ that reflect. What causes that...?

Carl: Well, they [windows] don't only reflect visible light, but also heat radiation, I guess... [gestures the path of a ray from the lamp to the window] which stays... I mean, bounces on the window...

JH: OK. So, if you compare visible light and IR light, in this case... what similarities and differences are there... in reflective capabilities... would you say....? /.../

Carl: Well, it should... there is more reflection, according to what we can see with the [IR] camera, compared to what we see... I mean, visually... [points to the window] because we don't see... well, if you look carefully, you see our... like, mirror images... but with this [directs the IR camera to the window and points to the screen] it is so much clearer.../.../

JH: So the glass seems to let through visible light more... than IR radiation. /.../ What's the functionality of a window... would you say...?

Anders: Insulation... and lighting...? [points to the window]

Carl: And letting in light... it's not meant to reflect that much light, because it's supposed to let light in... [gestures light coming in from the window] /.../ I mean, that's the idea... otherwise, there could have been a wall there.../.../ but it should also keep the heat inside, so it doesn't... otherwise, all wall insulation in the world wouldn't help...

JH: No, sure...

Carl: ...then the heat would get out through the windows.

JH: And does it seem to be working fine here, you think...?

Carl: Yes, it seems logical. 
In this investigation, Carl and Anders are fascinated when they see reflections of heat radiation from their bodies and lamps in the room with the IR camera. In contrast, visible-light reflections from such objects can hardly be seen in windows.

[Figure 1 about here]

In this way, similar to what was studied by Besson et al. (2010) (although without IR cameras), these (and other) students take an interest in how the optical behaviour of glass seems to depend on the wavelength of the radiation with which it interacts. In other words, by following in the footsteps of Scheele (1777/1780), they share his fascination of how glass lets through light, but shields heat radiation.

$\mathrm{JH}$ points the attention to the functionality of windows, and the students conclude that their observations make sense in relation to windows letting visible light in, while simultaneously providing thermal insulation. The way in which Carl and Anders interpret the heat reflections is insightful and largely accurate, which stands in stark contrast to the meagre outcomes of previous research on secondary students' and university engineering students' understanding of thermal radiation (e.g. Neumann and Hopf 2012, Jacobi et al. 2003). They express an understanding that visible light and IR radiation are electromagnetic radiation of different wavelengths, which can be reflected by or transmitted through a surface. In addition, even though the IR camera they use is a temperature measurement device, the students attend to the phenomenon that a glass window reflects IR radiation. They discern subtle mirror images of their bodies, which are shown on the screen in different nuances, and thereby take full advantage of the colour images on the screen in their investigation of heat radiation, as opposed to previously studied $7^{\text {th }}$-graders who rather focused on the numerical readings of IR cameras (Schönborn, Haglund, and Xie 2014). 
The example shows how students are empowered to investigate thermal phenomena in new ways by the IR camera's functionality, and the imagery it generates. That these two students came to focus on what windows look like with the IR camera, in the context of being interviewed by a researcher, is not a coincidence; many of the groups did the same, and also ended up drawing similar valuable conclusions regarding the thermal properties of the windows, which they in all likelihood would not have thought of without access to IR cameras. In other words, IR cameras add a new dimension of learning opportunity in thermal science by virtue of the disciplinary affordance it brings to the context (Fredlund et al. 2014).

This interaction is one of many examples where students in the current study came to investigate differences in properties of IR radiation and visible light, by comparing IR-camera images with their personal experiences of seeing visible light (Melander et al. 2016). Apart from the investigation of glass windows (Figure 1 and 2), students noticed IR reflections of their bodies on whiteboards (Figure 4), which are typically not seen in visible light. The other way around, IR radiation, as opposed to visible light, was seen to pass through a blown-up balloon. As previously seen, secondary students have tended to regard thermal reflections on IR images as mismeasurements of the temperature (Haglund et al. 2015a), or have experienced difficulties in interpreting them overall in a coherent way (Meiringer 2013). These differences in interpretation are probably due to the higher level of knowledge of thermal phenomena found amongst the university physics students in the current study, compared with students involved in previous research.

[Figure 2 about here]

Students who chose the task of investigating the functionality of IR cameras also often attended to the observation that electrical apparatus in the surroundings, such as video projectors or refrigerators, are markedly warmer than the surroundings (due to the involved energy 
transformations). One of the student pairs was particularly intrigued by an entrance card reader, which had a higher temperature than the outdoors surroundings. The students expressed that the card reader would be heated further due to conduction when a person enters a code, and the IR camera could potentially be used as a code-cracking device.

\section{White is the new black - investigating Leslie's cube}

Another pair of students chose the task of finding out more about the properties of thermal radiation, in particular by exploring the thermal properties of a Leslie's (1804) cube (Figure 2).

The week after their laboratory investigations, the students present what they have learnt to their peers and two of the researchers, one of whom was also running the laboratory exercise. After a brief introduction to electromagnetic radiation, Jöns, one of the students, starts to describe the outcome of the investigation undertaken by his group:

Jöns: OK, I'll talk a bit about the experiment we actually did. [shows a photo of a Leslie's cube] And for those of you who don't know, this is a Leslie’s cube. Usually it consists of a hollow copper cube that you fill with hot water, but in this case, it was made of aluminium, and there was a... [points inside the Leslie's cube on the picture] in here, there is a little light bulb... that is really warm... and a Leslie's cube is actually constructed in order to compare... the emissive capability of different... surfaces with different properties... or I should say... they are treated in different ways... so, in the case we see here... [points to a black side on the Leslie's cube] this side is pained matte black... and this one [a matte metal surface] is a bit... not polished... there was a shiny surface, as well... and there was also a white one, matte white...

Jöns describes the experimental set-up, with a Leslie’s cube with different surface properties, and turns to showing what it looks like with the IR camera (Figure 3):

Jöns: In order to measure the emissivity... [shows two IR images of two sides of the Leslie’s cube, see Fig. 4] Here [Figure 3, left] we see... I think this is the matte black side of the cube... and here [Figure 3, right] we have the shiniest side... and, as you see, other things are reflected... there is heat radiation... it reflects heat radiation, so... maybe you 
noticed, who took the camera and checked out the window... that you could wave at yourself in the window...

[Figure 3 about here]

Jöns describes the thermal properties of the four sides of the cube and says that shiny surfaces reflect heat radiation (an observation that was shared across the three reported episodes). Similar to what we saw in the first episode, he concludes that the IR images show reflections of heat radiation, rather than temperature changes of the measured surfaces.

Next, Jöns turns to the emissive properties of the painted surfaces (one black and one white):

Jöns: $\quad$ OK, the emissive capacity... is how well a material or a surface emits heat radiation... and what you maybe don't think of, which I found kind of cool... was that the matte black side... and the matte white side... they looked about the same in the IR camera. And when we read up on... about Leslie's cube, we noticed that... the colour doesn't have a really big impact on how well a surface emits heat radiation... but it is how shiny it is... and that was something I didn't know, because I always thought that dark objects absorb heat much better... it has some impact, but not that much, at all...

In their investigation, the students observed that the black and white surfaces of the Leslie's cube looked much the same on the IR camera screen, and concluded, in line with the findings of Bartels (1990) and Besson et al. (2010), that the painted surfaces have similar emissivity in the IR range, regardless of their colour. In contrast, there was a large difference in emissivity between, on the one hand, shiny metal surfaces (Figure 3, left), and, on the other, matte metal or painted surfaces (Figure 3, right).

Jöns expresses that this was a surprising finding. They had probably expected the black surface to have higher emissivity than the white surface, led by the expression 'black body radiation' and the experience of black surfaces absorbing visible light better than white surfaces. This shows indirectly awareness that surfaces that are good absorbers of radiation also are good 
emitters (as formalised in Kirchhoff's radiation law). However, their surprising observation was confirmed by consulting literature on the phenomenon (e.g. Bartels 1990), and complementary measurements with other equipment:

Jöns: We also had... we didn’t only have an IR camera... but we also had a little device that looked like a little flashlight [a thermal radiation sensor] that measured the heat radiation, and translated it into a voltage... and the matte colours, the white and the black, they weren't so far apart, when you looked at the voltage... but, in contrast, it dropped a great deal when you measured the shiny side...

Apart from the IR camera measurements, the groups of students that investigated thermal radiation had access to devices for point measurement of the electromagnetic intensity, and traditional thermometer probes.

All in all, Jöns shows a good understanding of how electromagnetic radiation of different wavelengths interacts with differently prepared surfaces. His presentation can be contrasted with the limited understanding of radiation previously expressed among physics students (Redfors and Ryder 2001), but resembles learning outcomes reported by Besson et al. (2010) from students’ practical exercises involving radiation.

\section{Horses for courses - comparing IR cameras with thermometers}

As in the first episode, another group - consisting of three students - also chose to explore the functionality of IR cameras. Gösta ends their slide-show presentation by sharing the pros and cons they see with the IR-camera technology in comparison to thermometers (shown in bullet point lists):

Gösta: [Shows first bullet point for IR cameras: “Holistic image”] So, you get a holistic image... when you use an IR camera... firstly... you have all used an IR camera... you get this kind of image... [gestures sweeping over a surface] this colour scale... and you also get specific... [gestures a point] you can home in on... a point of radiation... here, 
we want to see what the temperature is... but you still get... a large spectrum of what temperatures there are... on a particular surface...

Gösta sees the ability to render a colour image of the temperature spectrum of a surface, combined with the possibility to take point measures, as one of the distinct advantages of the IR-camera technology. Another advantage is that it can measure temperatures without direct contact:

Gösta: [Shows the next bullet point: "Contact not required”] Then, there’s... well, the IR camera does not require contact... so, if you for example are going to measure heat of something that is really, really warm, for example lava, then you cannot, like, stick down a thermometer... [gestures sticking down a thermometer] because then, it will disappear, burn up... and that is particularly good... and then, in an experiment, if something moves, it can be good... if you want to follow something with an IR camera... [gestures pointing to a moving target] instead of having to stick a thermometer onto it...

Objects of very high temperature and objects that move around are seen to be particularly well suited to IR-camera measurements. In this respect, it is interesting to note that the students do not bring up the possibilities to detect radiation from longer distances, such as for night-time surveillance or detecting forest fires from the air.

Gösta then turns to disadvantages:

Gösta: [Shows bullet point: “Expensive”] The drawback with an IR camera... they are typically expensive... if you compare with... I mean, IR cameras can cost about 10,000 crowns [in the Swedish currency, roughly equivalent to €1,000] often more than that... and then, if you compare to thermometers... you can get cheap ones for like 50 crowns... a bit more expensive, and it's still a few hundred... rather than in the thousands...

The high price of IR cameras is seen as one of the main drawbacks of the technology for educational purposes in comparison with cheap thermometers.

Next, Gösta points to the issue of reflections: 
Gösta: [Shows bullet point: "Reflections"] Another drawback with IR cameras... that is the reflection that you get from it... [shows an IR image of a person standing in front of a whiteboard, Figure 4] Here, we took a picture in front of... a white board... of just... Einar here... [points to the person rendered as having higher temperature than the surrounding room] we see him clearly here, but there are also the photons that are reflected on the whiteboard behind... and that can distort experiments and things... and it can be misinterpreted or misused... for example, people chasing ghosts and going on: “there is something behind here!” [laughter] So that’s definitely a drawback.

The previous two groups attended to the opportunities in exploring the reflective properties of different materials and surfaces by means of IR imaging. In contrast, but reminiscing of secondary students from previous studies (Haglund et al. 2015a), this group focuses on the drawbacks of reflections from shiny surfaces, such as a whiteboard. This is an important point to make, in relation to the use of IR imaging for making precision temperature measurements, where also assumptions of the emissivity of surfaces impact the accuracy of IR-camera readings.

[Figure 4 about here]

Finally, Gösta compares IR cameras with the functionality of thermometers. Thermometers are seen to have an advantage in relation to IR cameras in temperature measurement precision:

Gösta: [Shows bullet point for thermometers: "Higher resolution”] And then, with the thermometer... it gives a higher resolution... with an IR camera, it is a matter of 0.1 degrees Celsius... but with the thermometer, it can reach, like a thousandth of a degree Celsius.

The technologies also differ in that IR cameras measure the temperatures on the surface of objects, whereas thermometers can measure inside:

Gösta: [Shows bullet point: "Inner temperature”] And it also shows an inner temperature, a thermometer... as I told, when you've got an IR camera, it’s not optimal 
for cooking something, for example in the oven... if we have a chicken, we only see how warm it is on the surface... but if we want to get at the inner temperature, we need a thermometer that we can stick in [gestures sticking a thermometer into the chicken].

Here, Gösta recognises that IR cameras measure surface temperatures and thermometer probes can measure the temperature inside the bulk of objects, which means that they are useful for different applications. As the last reflection on the usefulness of thermometers, Gösta brings up the time for taking measurements:

Gösta: [Shows bullet point: “Time consuming”] A drawback, though, with a thermometer... is that it is time consuming... it measures the temperature by means of conduction... so it has to get... get in touch with something... [demonstrates physical contact with his hand on the bench] so that the heat is transferred to the thermometer... because that's really what a thermometer shows.

This shows a solid understanding of the different mechanisms of heat transfer that are utilised for IR imaging and thermometers, radiation and conduction, respectively, which otherwise has been found to be challenging also among university students (Jacobi et al. 2003).

\section{Discussion}

We now revisit the research question of the study, How do university physics students make use of IR cameras in open-ended investigation of thermal radiation as a phenomenon?, in the light of our findings, followed by a discussion of what implications there are for science education research and practice.

Overall, there is a striking contrast between the adequacy and security with which the students in the present study approached the involved thermal phenomena and laboratory equipment on one hand, and the challenges with grasping thermal radiation that have been reported in educational research among students of different ages in physics and other related disciplines, such as engineering (e.g. Neumann and Hopf 2012, Jacobi et al. 2003), on the other. 
In this respect, the students' interaction with IR cameras and resulting discussions in openended laboratory activities are impressive.

As mentioned, secondary students have been found to regard IR cameras primarily as visual thermometers, sometimes involving distortions due to reflections (Haglund et al. 2015a). In contrast, in the present study, undergraduate students saw the IR imaging technology as a way to investigate IR radiation, and to compare it with the thermal and optical properties of visible light. In particular, the students were fascinated with the fact that IR radiation tends to reflect on shiny surfaces, such as windows, whiteboards, and shiny metal surfaces, to a greater extent than visible light. In addition, it was surprising for students to see that metal surfaces painted black and white have comparable emissive properties in the IR spectrum.

The benefit of IR cameras was particularly pronounced for two of the seven phenomena the students could choose from: electromagnetic radiation, and the function of the IR camera. Consequently, these were in focus in the current study. The IR cameras were useful for other phenomena as well, such as for discerning the temperatures of the different components of a heat pump or seeing the cooling of the fire extinguisher and surrounding as $\mathrm{CO}_{2}$ is let out (Melander et al. 2016). For such phenomena, however, IR imaging did not help the students realise the centrality of phase changes of the refrigerant or $\mathrm{CO}_{2}$, respectively, which has previously been recognised as challenging to physics students (Georgiou, Maton, and Sharma 2014). This is not surprising, since the IR camera shows the temperature on the outside surface of the equipment, not of the fluids inside, and the students were not encouraged to provide microscopic explanations. Similarly, in line with the findings of Redfors and Ryder (2001), the students were not inclined to provide microscopic explanations of the interaction between thermal radiation and metals, assumingly due to the macroscopic emphasis of IR imaging.

\section{Implications for science education research and practice}

As reported previously (e.g. Vollmer et al. 2001, Xie and Hazzard 2011), IR cameras are a 
powerful tool in the investigation of heat-related phenomena in many science and engineering sub-fields. The current study emphasises the usefulness of IR cameras in the investigation of thermal radiation. As we have seen, thermal radiation has been identified as particularly challenging for students in university physics (Redfors and Ryder 2001), and related areas such as secondary physics (Neumann and Hopf 2012) and university engineering (Jacobi et al. 2003).

In addition, the findings of our research here support the view of Xie and Hazzard (2011) in that IR cameras are particularly well suited for supporting open-ended inquiry-based approaches to laboratory investigations, due to their versatility and user-friendliness. Similar to what has been identified among science-museum laypeople visitors (Atkins et al. 2009), and

primary and secondary students (Haglund et al. 2015a, Haglund, Jeppsson, and Schönborn 2016), this study shows that also undergraduate physics students are prone to engage in creative inquiry of thermal phenomena when given the opportunity to engage with an IR camera. The use of IR cameras thereby helped making thermodynamics more visible and opened up for dialogue about the experienced phenomena. The interaction with them thus contributed to addressing the challenge that students tend to see the subject as difficult and uninteresting (Ugursal and Cruickshank 2015).

This study gives examples of how IR cameras can be a valuable tool in university physics students’ open-ended laboratory investigation of thermal radiation. Further research in needed in the exploration of how IR cameras can support students' understanding of other topics in thermodynamics, within the disciplines of physics (e.g. thermodynamic processes), chemistry (e.g. chemical reactions), and engineering (e.g. the mechanisms of heat transfer).

\section{Acknowledgements}

First of all, we would like to thank the students, who took part in the study. We are also grateful towards FLIR, who kindly lent us a FLIR C2 IR camera for the exercises, and shared still images 
of student interaction. Furthermore, we much appreciated valuable suggestions to the text from Cedric Linder and Konrad Schönborn.

This work was supported by the Faculty of Science and Technology Pedagogical Renewal Fund at Uppsala University; and by the Centre for Discipline-Based Education Research in Mathematics, Engineering, Science and Technology at Uppsala University.

\section{References}

Atkins, Leslie J, Lisanne Velez, David Goudy, and Kevin Dunbar. 2009. "The unintended effects of interactive objects and labels in the science museum." Science Education 93 (1):161-184.

Bacon, Francis. 1620/2000. The new organon. Cambridge, UK: Cambridge University Press. Bain, Kinsey, Alena Moon, Michael R Mack, and Marcy H Towns. 2014. "A review of research on the teaching and learning of thermodynamics at the university level." Chemistry Education Research and Practice 15 (3):320-335.

Bartels, Richard A. 1990. "Do darker objects really cool faster?" American Journal of Physics 58 (3):244-248.

Besson, Ugo, Anna De Ambrosis, and Paolo Mascheretti. 2010. "Studying the physical basis of global warming: thermal effects of the interaction between radiation and matter and greenhouse effect." European Journal of Physics 31 (2):375-388.

Çengel, Yunus A., and Robert H. Turner. 2005. Fundamentals of thermal-fluid sciences. Boston, MA: McGraw-Hill.

Cohen, Louis, Lawrence Manion, and Keith Morrison. 2011. Research methods in education. 7 ed. Milton Park, UK: Routledge.

Cornell, E S. 1936. "Early studies in radiant heat." Annals of Science 1 (2):217-225. 
Domin, Daniel S. 1999. "A review of laboratory instruction styles." Journal of Chemical Education 76 (4):543-547.

Dreyfus, Benjamin W, Benjamin D Geller, David E Meltzer, and Vashti Sawtelle. 2015. "Resource letter TTSM-1: Teaching thermodynamics and statistical mechanics in introductory physics, chemistry, and biology." American Journal of Physics 83 (1):521.

Fredlund, Tobias, Cedric Linder, John Airey, and Anne Linder. 2014. "Unpacking physics representations: Towards an appreciation of disciplinary affordance." Physical Review Special Topics - Physics Education Research 10 (2):020129.

Georgiou, Helen, Karl Maton, and Manjula Sharma. 2014. "Recovering knowledge for science education research: Exploring the "icarus effect” in student work." Canadian Journal of Science, Mathematics and Technology Education 14 (3):252-268.

Haglund, Jesper, Fredrik Jeppsson, David Hedberg, and Konrad J Schönborn. 2015a. "Students' framing of laboratory exercises using infrared cameras." Physical Review Special Topics - Physics Education Research 11 (2):020127.

Haglund, Jesper, Fredrik Jeppsson, David Hedberg, and Konrad J Schönborn. 2015b. "Thermal cameras in school laboratory activities." Physics Education 50 (4):424-430. Haglund, Jesper, Fredrik Jeppsson, and Konrad J Schönborn. 2016. "Taking on the heat - a narrative account of how infrared cameras invite instant inquiry." Research in Science Education 46 (5):685-713.

Hake, Richard R. 1998. "Interactive-engagement versus traditional methods: A six-thousandstudent survey of mechanics test data for introductory physics courses." American Journal of Physics 66 (1):64-74.

Herschel, William. 1800. "Experiments on the refrangibility of the invisible rays of the sun." Philosophical Transactions of the Royal Society of London 90:284-292. 
Hestenes, David, Malcolm Wells, and Gregg Swackhamer. 1992. "The force concept inventory." The Physics Teacher 30 (3):141-158.

Hofstein, Avi, and Vincent N Lunetta. 2004. "The laboratory in science education: Foundations for the twenty-first century." Science Education 88 (1):28-54.

Jacobi, Anthony, Jay Martin, John Mitchell, and Ty Newell. 2003. "A concept inventory for heat transfer." 33rd ASEE/IEEE Frontiers in Education Conference, 2003, University of Colorado, Boulder.

Laws, Priscilla W, Robert J Boyle, Patrick J Conney, Kenneth L Laws, John W Leutzelschwab, David R Sokoloff, and Ronald K Thornton. 1997. Workshop physics activity guide. New York, NY: John Wiley \& Sons.

Leslie, John. 1804. An experimental inquiry into the nature and propagation of heat. London, UK: Mawman.

Lewis, Eileen L, and Marcia C Linn. 1994. "Heat energy and temperature concepts of adolescents, adults, and experts: implications for curricular improvements." Journal of Research in Science Teaching 31 (6):657-678.

Maxwell, J Clerk. 1865. "A dynamical theory of the electromagnetic field." Philosophical Transactions of the Royal Society of London 155:459-512.

Meiringer, Markus. 2013. "Schülerforstellungen zur Infrarotkamera und deren Aufnahmen (Student conceptions of infrared cameras and their images)."Master thesis, Universität Wien.

Melander, Emil, Cecilia Gustavsson, and Matthias Weiszflog. 2013. "Development of laboratory exercises in thermodynamics." 4:e utvecklingskonferensen för Sveriges ingenjörsutbildningar, Umeå, 27-28 November. 
Melander, Emil, Jesper Haglund, Matthias Weiszflog, and Staffan Andersson. 2016. "More than meets the eye - infrared cameras in open-ended university thermodynamics labs." The Physics Teacher 54 (9):528-531.

Möllmann, Klaus-Peter, and Michael Vollmer. 2007. "Infrared thermal imaging as a tool in university physics education." European Journal of Physics 28 (3):S37-S50.

Neumann, Susanne, and Martin Hopf. 2012. "Students’ conceptions about 'radiation': Results from an explorative interview study of 9th grade students." Journal of Science Education and Technology 21 (6):826-834.

Olson, Richard G. 1969. "A note on Leslie's cube in the study of radiant heat." Annals of Science 25 (3):203-208.

Planck, Max. 1901. "Ueber das Gesetz der Energieverteilung im Normalspectrum [On the law of the energy distribution in the normal spectrum]." Annalen der Physik 309 (3):553563.

Planinsic, Gorazd. 2015. "There is more about light than our eyes can see." accessed 15 February. http://c.ymcdn.com/sites/www.eps.org/resource/collection/67127A00-1D90-

\section{E-A2E2-}

41BEEBF43B49/Everyday_Objects_in_Visible_and_Infrared_Light_Teachers_guide.p df.

Prince, Michael, Margot Vigeant, and Katharyn Nottis. 2012a. "Development of the Heat and Energy Concept Inventory: Preliminary results on the prevalence and persistence of engineering students' misconceptions." Journal of Engineering Education 101 (3):412438.

Prince, Michael, Margot Vigeant, and Katharyn Nottis. 2012b. "Using inquiry-based activities to repair student misconceptions related to heat, energy and temperature." Frontiers in Education Conference, 3-6 October, Seattle, WA. 
Redfors, Andreas, and Jim Ryder. 2001. "University physics students’ use of models in explanations of phenomena involving interaction between metals and electromagnetic radiation." International Journal of Science Education 23 (12):1283-1301.

Scheele, Carl Wilhelm. 1777/1780. Chemical observations and experiments on air and fire. Translated by J R Forster. London, UK: Johnson.

Schönborn, Konrad J, Jesper Haglund, and Charles Xie. 2014. "Pupils’ early explorations of thermoimaging to interpret heat and temperature." Journal of Baltic Science Education $13(1): 118-132$.

The_Engineering_Toolbox. 2016. "Emissivity coefficients of some common materials." accessed 15 February. http://www.engineeringtoolbox.com/emissivity-coefficientsd_ 447.html.

Tobin, Kenneth. 1990. "Research on science laboratory activities: In pursuit of better questions and answers to improve learning." School Science and Mathematics 90 (5):403-418.

Ugursal, V Ismet, and Cynthia A Cruickshank. 2015. "Student opinions and perceptions of undergraduate thermodynamics courses in engineering." European Journal of Engineering Education 40 (6):593-610.

White, Richard, and Richard Gunstone. 1992. Probing understanding. London, UK: The Falmer Press.

Viennot, Laurence, and Nicolas Décamp. 2016. "Codevelopment of conceptual understanding and critical attitude: toward a systemic analysis of the survival blanket." European Journal of Physics 37 (1):015702.

Vollmer, Michael, and Klaus-Peter Möllmann. 2010. Infrared thermal imaging: fundamentals, research and applications. Weinheim, Germany: Wiley-VCH. 
Vollmer, Michael, Klaus-Peter Möllmann, Frank Pinno, and Detlef Karstädt. 2001. "There is more to see than eyes can detect - Visualization of energy transfer processes and the laws of radiation for physics education." The Physics Teacher 39 (6):371-376.

Xie, Charles. 2011. "Visualizing chemistry with infrared imaging." Journal of Chemical Education 88 (7):881-885.

Xie, Charles, and Edmund Hazzard. 2011. "Infrared imaging for inquiry-based learning." The Physics Teacher 49 (6):368-372. 


\section{Figure captions}
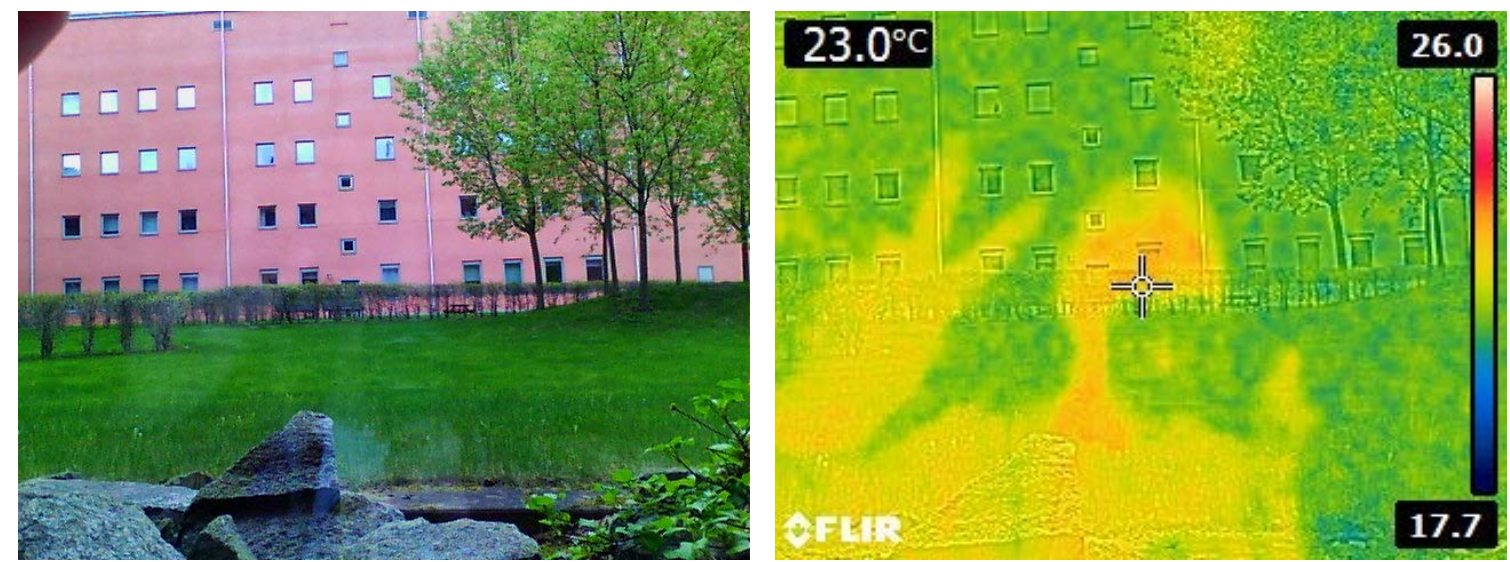

Figure 1. A photo of the laboratory surroundings, taken through a window, with barely visible reflections (left); the corresponding superimposed IR image, where IR radiation reflections from the photographer student are clearly visible (right)
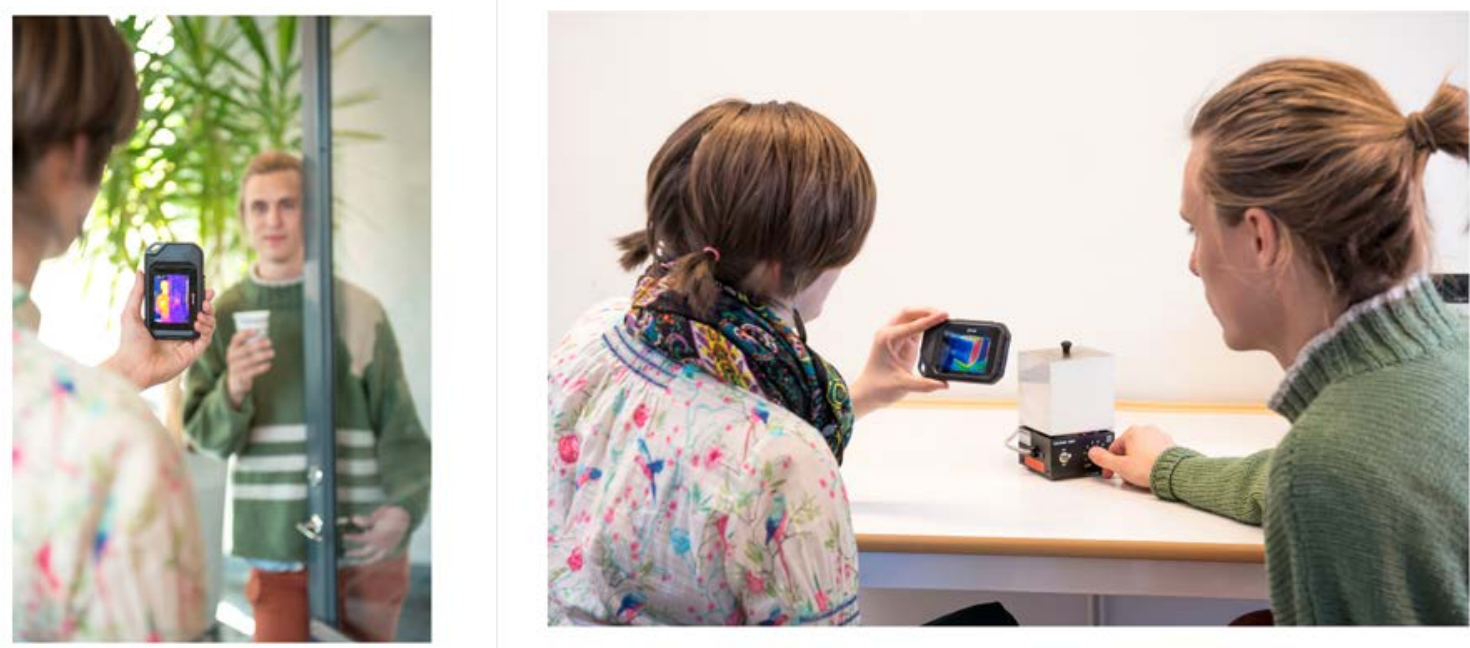

Figure 2. Photo of a pair of students, who investigate the thermal properties of a window glass with an IR camera (left); photo of a pair of students, who observe the shiny metal and matte metal sides of a Leslie’s cube with an IR camera (right) 

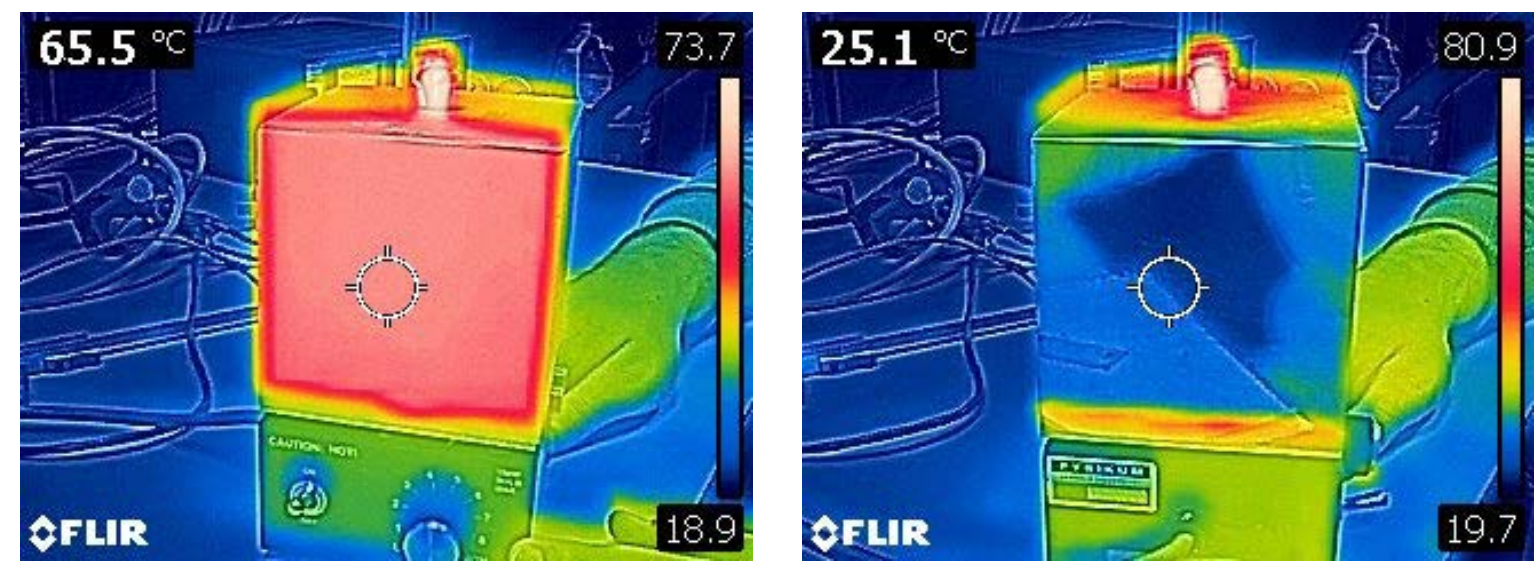

Figure 3. IR images of a Leslie's cube, which show the difference in IR radiation being emitted from a matte painted surface (left) and a polished metal surface (right), of roughly the same temperature, due to different emissivity. The right image also shows reflections of radiation from the surrounding

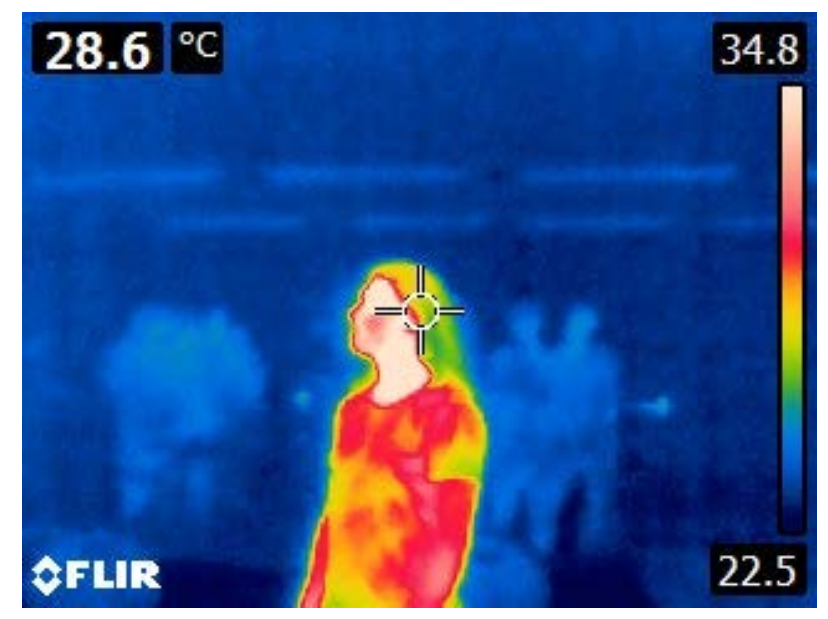

Figure 4. IR image of a student, Einar, standing in front of a whiteboard, with reflections of IR radiation from other students and lamps in the backgroundx§ 